\title{
How Context Matters: A Survey Based Experiment on Distributive Justice*
}

\author{
Marco Faravelli ${ }^{\dagger}$
}

\begin{abstract}
We explore distributive justice and perception of fairness using survey data from freshmen and senior students of economics and sociology. We analyse the impact of context and education on their preferences over a hypothetical distribution of resources between individuals which presents a trade off between efficiency and equality. With context giving minimal information, economics students are less likely to favour equality; studying economics influences the preferences of the subjects, increasing this difference. However, when the same problem is inserted into a meaningful context, the difference disappears. Four distribution mechanisms are analysed: egalitarianism, maximin, utilitarianism and utilitarianism with a floor constraint.
\end{abstract}

\section{Introduction}

One of the most interesting results that arises from dictator and ultimatum experiments is that fairness seems to be a strong concern. Experimental results on the ultimatum game show that a large fraction of players offer a "fair" allocation and that "unfair" offers are systematically rejected. Furthermore, while economists tend to evaluate allocations purely quantitatively, these experimental data also suggest that whether an allocation is seen as "fair" can depend on qualitative factors, the context in which it is presented and the way it is framed. In addition, the data from dictator experiments suggest that there is significant heterogeneity in what people consider fair, with many people giving nothing as well as many splitting the available resources equally.

The main motivation for the present study is the further investigation of this evidence. However, we will not employ a game theoretical approach. This paper is a survey based investigation of perception of fairness and attitudes towards distributive

${ }^{*}$ I would like to thank Ed Hopkins, Tatiana Kornienko and two anonymous referees for useful comments and suggestions. I am also grateful to Robert Penney and Emma Seel for their contributions to this paper. Errors remain my own.

${ }^{\dagger}$ Edinburgh School of Economics, William Robertson Building 50 George Square, Edinburgh EH8 9JY, UK. Economics Department, University of Milan Bicocca, Piazza dell'Ateneo Nuovo 1, 20126 Milan, Italy. E-mail: M.Faravelli@sms.ed.ac.uk. 
justice. We focus on unbiased justice, or justice from the viewpoint of an "impartial spectator", in comparison to many other studies that involve stakes and analyse the effect of fairness on the stakeholders.

Our aim is twofold. First, we wish to analyse how context influences preferences over a hypothetical distribution of resources and in what way adding justice-related information to the context affects judgements. Second, we explore the impact of education on perception of fairness. We surveyed both first and last year undergraduate students of economics and sociology (hereafter referred to as freshmen and seniors). We submitted to them different versions of a problem involving the distribution of resources between two individuals in which we asked them to choose the distribution that they considered the most fair. The two individuals obtain a different utility from the resources and there is, therefore, a trade off between efficiency, which involves handing more resources to the more productive individual, and equality, which might demand an equal division even if that would not maximise total output. We will refer to this problem as the distribution problem. We found that, with a context giving minimal information, economics students were less likely to favour equality than sociology students and this difference was more marked in senior students. Thus, studying economics seemed to have influenced the preferences of the subjects over the distribution of resources, while we found no significant difference between the choices of sociology freshmen and seniors. This evidence suggests that previous survey studies carried out on economics students (see for example Engelmann and Strobel, 2004) might have obtained different results with a different subject population. However, when the same question was rephrased to give a meaningful context, there was now significant agreement over which allocation was fairest and there was no significant difference between economics and sociology students.

Let us consider the first of our aims. It is well known that perception of fairness and behaviour related to fairness judgements are context dependent. The set of individuals being compared, the type of good being distributed, the historical terms of transactions or the framing of information are all examples of contextual elements. Probably the most cited study of justice in economics that emphisises the variation of views of fairness with context is that of Kahneman, Knetsch, and Thaler (1986). We are interested on how such judgements are related to various classes of context. One of the first examples of studies in this direction is that of Yaari and Bar-Hillel (1984), who analysed how judgements are affected by context when it specifies whether individuals need the goods to be distributed or they simply like them. There exists by now a large economic literature on this topic (see Schokkaert and Overlaet, 1989; Gaertner, 1994; Gaertner, Jungeilges, and Neck, 2001; Gaertner and Jungeilges, 2002; Schokkaert and Devooght, 2003; Gaertner and Schwettmann, 2005, among others) as well as a lot of evidence from the psychological and sociological literature (for an overview see Konow 2003).

As we will explain in Section 2, we consider the specific problem of how intuitions of fairness vary with contextual factors which determine whether or not individuals are responsible for the outcomes of their actions. Several papers from the social choice literature have addressed this issue (e.g., see Schokkaert and Lagrou, 1983; Schokkaert 
and Overlaet, 1989; Schokkaert and Devooght, 2003; Cappelen, Sørensen, and Tungodden, 2005; Gaertner and Schwettmann, 2005), and a survey of the economic and the psychological literature on this topic can be found in Konow (2003). We wish to examine how the relative importance of equality and efficiency can depend on these factors, and which distributions are considered fair given the type of context. Further, we are interested in assessing whether clearly specifying the type of context helps overcome the (possible) differences in judgments between economics and sociology students and between freshmen and seniors. The evidence that additional information facilitates the attainment of a more widespread consensus on what is fair is an important finding for public debates ${ }^{1}$. Given that individuals' judgements may vary according to education, profession and age, amongst other categories, this finding should hopefully allow progress in controversial policy debates.

We investigated four versions of the distribution problem. The versions are all formally identical, but each of them is characterised by a different context. In the first version no explanation of the difference between the two individuals is provided. The second and the third versions present two distinct explanations: in one, the second individual is less productive because he is handicapped, in the other, because he works less hard. The same possible allocations are present in all versions of the problem: an egalitarian, a utilitarian and a maximin allocation. Context had a significant effect on what the subjects thought was fair and led to greater level of agreement between the parties: the maximin allocation was preferred when the difference was due to a handicap; in case of a different effort the utilitarian distribution was chosen. People tend to favour the less productive individual when different outcomes are due to external causes (for instance a handicap), but they will punish him if the cause is internal (for instance for exerting less effort). The two situations are perceived differently and imply distinct reasons for allocating resources. People tend to distribute according to need when abilities are different, and according to efficiency when there is difference in effort. The fourth version presents no explanation of the difference between the two individuals, but a floor is introduced in terms of minimum utility necessary for each individual. The tension here is that the efficient allocation does not give the minimum survival utility to the less efficient individual. As well as the previous allocations, a fourth allocation is permitted, deriving from the application of utilitarianism with a floor.

Our hypothesis is that when no explanation of the difference between the individuals is provided, the subjects involuntarily insert the distribution problem into a determined context, filling the lack of information according to their personal attitudes and background. The preference for a particular allocation under this condition will reveal the relative concern of the subject for either the efficiency or the equality of the distribution. We will refer to such a preference as the "ideology" of the subject.

Our second purpose is to investigate the influence of education on perception of fairness. While a few studies have focused on differences in judgement (e.g., see Mar-

\footnotetext{
${ }^{1}$ Interestingly Babcock et al. (1995) report the opposite result, i.e. adding information increases bias. The difference is that the participants in their study have a monetary incentive, so information is employed in a biased way.
} 
well and Ames, 1981; Amiel and Cowell, 1999, for a summary of their findings), most of the literature on the differences between economists and non-economists has concentrated on their behaviour. Several experiments have been conducted to ascertain and to analyse any different behaviours in terms of propensity to co-operate (through prisoner's dilemma games), to free ride (for instance, in the provision of public goods) or in the degree of selfishness.

Both experiments with monetary incentives and surveys are valuable instruments to explore fairness, according to the purpose of the analysis. Differences in judgement can be as relevant as differences in behaviour, depending on the situation and the circumstances. In daily life people's intuitions of fairness determine not only their behaviour but also their judgements of situations in which they are not directly involved. People often act on unbiased views when their stakes are low or negligible, for example as voters or in the case of juries. Further, even when personal stakes are relatively high and agents trade-off self-interest and social preferences, it is interesting to examine the fairness point against which the self-interest point is being traded off. Economists participate in boards, are members of councils, vote and legislate. It is important to analyse whether their judgements differ from other people's and to what extent this is context-related. When the purpose is to explore intuitions of fairness, eliminating monetary stakes reduces self-interest bias and presents the advantage of encouraging "participants to prescind and abstract from personal stakes" (Konow 2003, p. 1191) ${ }^{2}$.

In conducting our analysis, we will proceed as follows. Having found that an ideological difference does exist we will show that a significant agreement can be reached clarifying the context of the distribution. Further, we have to investigate the reasons for this difference. The literature that compares economists and non-economists suggests that the differences could be due to two causes. They may be the result of a self-selection process or of training in economics. These two conjectures have been called the selection and the learning hypothesis (Carter and Irons, 1991). Comparing the answers of freshmen students of the two courses will show the existence of a selection effect. Comparing the answers given by freshmen and senior students of the same course, we will find that a learning effect only exists for economics students.

In Section 2 we will discuss how context relates to responsibility concerns and present the distribution mechanisms examined in our analysis. Section 3 reports the results of the most prominent experiments directed to compare economists and non-economists. In Section 4 we will discuss the design of the questionnaire and the hypotheses that we are going to test. Section 5 displays the results. Section 6 concludes.

\section{Equality, Efficiency and Responsibility}

In any discussion of fairness and justice theories a fundamental issue is the conflict between equality and efficiency. In an excellent survey on positive and normative theories of justice James Konow (2003) examines this contrast describing the principles that are

\footnotetext{
${ }^{2}$ See also Fong (2001).
} 
behind these concepts: the Need Principle and the Efficiency Principle. The former invokes the equal satisfaction of basic needs and inspires theories such as egalitarianism and Rawls' theory of justice (1971). The latter advocates maximising surplus and is most closely associated with utilitarianism.

We examine the problem of how the balance between efficiency and equality is influenced by responsibility considerations. Further we wish to verify whether inserting the problem into a meaningful context, which clearly states who can be held accountable for a certain outcome and who cannot, leads to a greater consensus on what is considered just.

The issue of responsibility has been investigated by philosophers as well as by economists and psychologists, focusing mainly on two questions. First, how to characterise responsibility and what does make a person accountable for an outcome. The second question is related to the critique of the welfarist interpretation (see Fleurbaey, 1998, for a survey of this literature). Sen (1992) defines the set of welfarist theories as those theories that take utilities as the only relevant personal features and differ between them in the choice of combining characteristics. The insufficiency of the welfarist framework to capture the complexity of the distribution problem was already the main conclusion reached by Yaari and Bar-Hillel (1984) and several subsequent questionnaire-studies abandoned the welfarist perspective in their analysis (see Schokkaert and Overlaet, 1989; Gaertner, 1994; Gaertner, Jungeilges, and Neck, 2001; Gaertner and Jungeilges, 2002; Schokkaert and Devooght, 2003; Gaertner and Schwettmann, 2005, among others). Further, there exists by now a large literature in social choice about how to incorporate ideas of responsibility in the social evaluations (for an overview see Fleurbaey and Maniquet, forthcoming). Although we appreciate the importance of this literature, we are mainly concerned with the first question, that is the issue of characterising responsibility. Given the goals of our investigation, it seemed somewhat clearer to adopt a welfarist interpretation without adding further complications to the analysis and we believe that our results correctly represent the moral intuitions of the subjects.

Although a concern for individual responsibility was present in Rawls (1971) and Sen (1980), with regards to primary goods and functionings respectively, Dworkin (1981) has been the first among political philosophers to explicitly focus on this issue. Dworkin considers that a person must be held responsible for her preferences whether or not they are voluntarily cultivated, as long as she identifies with them, but she cannot be held accountable for her resources. He also makes a helpful distinction between "option luck", which is the output of a gamble explicitly taken, and "brute luck", which is an output in which no gamble was entered into. Thus option luck is a matter of choice and hence fair, while brute luck is morally arbitrary and therefore unfair. Arneson (1989, 1990) and Cohen (1989) proposed a revision of what Cohen (1989) called "Dworkin's cut", that is the division between preferences and resources. Although they articulate their positions differently,.both these authors agree that the "right cut is between responsibility and bad luck, not between preferences and resources" (Cohen, 1989, p. 921). The debate is far from being closed and Roemer (1993) has introduced a relativistic position, proposing that the cut between responsibility and compensation 
can be seen as cultural-dependent.

Economists have analysed the importance of responsibility considerations in perception of fairness through several questionnaire-studies and experiments and have tried to single out which characteristics are considered to be within the control of an individual and which are not (see Schokkaert and Lagrou, 1983; Schokkaert and Overlaet, 1989; Schokkaert and Devooght, 2003; Cappelen, Sørensen, and Tungodden, 2005; Gaertner and Schwettmann, 2005, among others). A thorough review of this literature and its relations with social psychology can be found in Konow (2003). The author reports the results of several experiments and surveys in economics and in psychology that indicate that individuals are held accountable for their effort and choices that affect their contribution, but they are not considered responsible for their birth, brute luck and choices that do not affect their productivity. Such results seem to confirm the predictions of attribution theory. Attribution theory is a social psychology theory initiated by Heider (1958) that explains behaviour on the basis of causal attributions of responsibility. According to this theory, people infer causes of events and evaluate to what extent an agent has contributed to the outcome, holding the agent responsible only for those factors that the agent can influence. As Konow (2003) suggests "attribution theory provides a powerful criterion for describing desert according to the views of most people" (p. 1214).

In our empirical investigation, we build a distribution problem such that the theories inspired by the Need Principle advocate allocations of resources substantially different from the distribution that would result if the Efficiency Principle was applied. In the base treatment, where the context of the problem is not clarified, it is not clear what the different productivity of the two individuals depends on. We then examine two classes of context, which fill the gap of information and enable the subjects to establish whether the agents can or cannot be held accountable for their productivity. In one the different productivity is explained in terms of brute luck, a factor that is out of the control of the individuals; in the other it depends on effort, an element that they can control. Following Konow (2000) we will refer to "exogenous differences" in the first case and "discretionary differences" in the second. Finally we consider a version of the distribution problem in which "need" considerations are involved; this treatment is identical to the first one except for the introduction of a threshold under which the individuals do not survive.

Let us consider the distribution mechanisms that will be examined in our analysis. Besides the Egalitarian solution we are going to consider three other distribution mechanisms, whose application may determine particular departures from equality. Let us examine these distribution principles.

Many different forms of utilitarianism exist, but we will refer to it as the principle that advocates the maximisation of the sum of individual utilities.

Rawls' (1971) theory of justice was conceived as an alternative to utilitarianism, in all of its forms, and has become a powerful contestant to utilitarian theory in recent years. Rawls proposes two principles of justice that are meant to rule the basic structure of society and determine the division of advantages of social cooperation. The above 
principles would result from a social contract made by rational individuals behind a "veil of ignorance", which would guarantee the impartiality of the parties. While the first principle rules the scheme of liberties each person has the right to, the second principle determines which social and economic inequalities are acceptable. The distribution mechanism we are interested in is what Rawls refers to as the maximin equity criterion, which came subsequently to be known as the difference principle. It is identifiable with the first part of the second principle, which is defined as following: "Social and economic inequalities are to meet two conditions: they must be (a) to the greatest expected benefit of the least advantaged members of society (the maximin equity criterion) and (b) attached to offices and positions open to all under conditions of fair equality of opportunity." (Rawls, 1974, p. 142). This criterion is clearly opposed to the utilitarian that only cares about maximising utility regardless of its distribution.

Finally, utilitarianism with a floor is a mechanism that prescribes the maximisation of the average utility with a floor constraint. Preferences for distributions prescribed by the application of this principle have been tested in several experiments (e.g. Frohlich, Oppenheimer, and Eavy, 1987a, 1987b; Lissowsky, Tyszka, and Okrasa, 1991).

Rawls' theory of justice's informational basis does not coincide with the utilitarian. In the utilitarian theory the informational basis consists only of the utilities of the individuals in the states of affairs under evaluation. Rawls' theory, on the contrary, ranks the different states of affairs according to the distribution of primary goods, that are defined as anything any rational person wants and will want regardless of his plan of life or his place in the social scheme. As we mentioned above we are going to consider all of the distribution mechanisms discussed, including the maximin criterion, from a welfarist perspective. Among the welfarist theories, Sen (1992) recalls the utility-based maximin as that distribution mechanism that prescribes to maximise the utility of the least advantaged individual. This is the interpretation that we are going to assume in the course of our analysis.

\section{$3 \quad$ Are Economists Different?}

Most of the literature on the differences between economists and non-economists has concentrated on differences in behaviour. Amiel and Cowell (1999) summarise some of their findings on the different moral intuitions of economists and non-economists. They focused mainly on the acceptance of the monotonicity axiom, a concept which is very close to the Pareto principle ${ }^{3}$. Their results show that the monotonicity axiom was not a very popular concept. However, it was generally accepted more favourably by economics students than by their sociologist colleagues.

Marwell and Ames (1981) conducted the first study that compared economists and non-economists, through an experiment that called for private contributions to public goods. They found that first-year graduate students in economics are much more likely

\footnotetext{
${ }^{3}$ While the Pareto criterion is expressed in terms of utility "the monotonicity axiom is usually put in terms of persons' incomes" (Amiel and Cowell, 1999, p. 64).
} 
than others to free ride. They conjectured that there might be two reasons for why economists might behave differently, defined by Carter and Irons (1991) as the selection and the learning hypothesis. However, Marwell and Ames did not check the extent to which this difference is due to one hypothesis or the other (or to both of them). Further, they collected a wide range of information regarding the different perceptions, expectations and explanations for the behaviour of the subjects. Two questions were asked. First, what is a fair investment in the public good? 75 percent of the noneconomists answered "half or more" of the endowment, and 25 percent answered "all". The other question asked whether they were concerned about fairness in making their own investment decision. Almost all non-economists answered "yes". The answers of the economics students were more difficult to analyse. More than one-third of them either refused to answer the first question or gave uncodable responses. As Marwell and Ames wrote, "it seems that the meaning of 'fairness' in this context was somewhat alien for this group" (Marwell and Ames, 1981, p. 309). Those who did answer found that little or no contribution was fair. With regard to the second question, economics students were much less concerned with fairness when making their decisions.

Carter and Irons (1991) investigated the behaviour of students of economics compared to students of other disciplines in an ultimatum bargaining game. They found that economics students behaved more self-interestedly than other students. They tested the selection and the learning hypothesis, finding that "economists are born, not made" (Carter and Irons, 1991, p. 174). They claimed that studying economics does not create rational, self-interested homines economici, but subjects who are particularly concerned with economic incentives self-select into economics. Using a prisoner's dilemma game, Frank, Gilovich, and Regan (1993) found that economists behave in more self-interested ways and are much more likely to defect from coalitions. Further, their results support the learning hypothesis. According to them, "exposure to the selfinterest model does in fact encourage self-interested behavior" (Frank, Gilovich, and Regan, 1993, p. 159) and inhibit co-operation.

Yezer, Goldfarb, and Poppen (1996) strongly criticised the results obtained by Frank and his coauthors (1993) from a methodological point of view. They claimed that the evidence of that paper only implies that economics students display uncooperative behaviour in specialised games. They conducted a "lost-letter" experiment, in which envelopes containing currency are dropped in classrooms before the beginning of the lectures. The return rate on lost letters is used as a measure of co-operation. According to their results, the "real life" behaviour of economics students is actually more cooperative than that of subjects studying other disciplines. Similarly, Frey and Meier (2003) claim that "students may play the equilibrium learned in their economics classes, but they do not apply it to real life situations" (Frey and Meier, 2003, p. 448). Further, their results indicate that the particular behaviour of economists is only due to selfselection. On the basis of Yezer's results, Zsolnai (2003) suggests that there might be no contradiction between honesty and co-operation, which are two different qualities, and claims that economists' behaviour is characterised by respect for property rights and self-interest motivation simultaneously. Finally, Hu and Liu (2003) found evidence 
that economics students are more likely to co-operate in prisoner's dilemma games.

In sum, the results are inconclusive and depend on the different settings. Further, most of these studies are aimed to test whether economics students behave more in accordance with predictions of the rational/self-interest model of economics. However, despite the different approach assumed in this work, it will be useful, in the course of our analysis, to compare the above results with ours, taking into account the different perspectives assumed.

\section{Methods and Hypotheses}

In March 2002, a total of 1333 students of the University of Milan took part in the survey. 661 of them were sociology students, 345 freshmen and 316 seniors. The remaining 672 were economics students, 354 freshmen and 318 seniors. In each of the four groups women and men were present in approximately equal number. Regarding these groups there are two important points to make. First, nobody, among the freshmen, had studied economics in the previous years of school. Second, the freshmen of economics had not started economic topics yet, having only studied mathematics, statistics and law courses. Participation was voluntary and all those asked to participate agreed to do so. There was no show-up fee paid. Each student was given a sheet containing on the front the base problem and on the back, at random, one of the remaining three problems. Thus, each of the four groups was divided into three classes, according to the nature of the second question. Students were asked to read the question on the front and only after answering that they could read and answer the one on the back. It was not possible to change the answer to the first problem after reading the second one. The total time for conducting the questionnaire, including our instructions, varied between 20 and 25 minutes, due to the difference in class sizes.

The four questions are reported in Appendix A. We will refer to them as question 1 (base treatment), question $2 \mathrm{a}$ (exogenous difference treatment), question $2 \mathrm{~b}$ (discretionary difference treatment) and question 2c (need treatment). All of the respondents answered question 1. 464 students answered question 2a; of them, 124 were economics freshmen, 115 economics seniors, 134 sociology freshmen and 91 sociology seniors. Question 2b was submitted to 451 respondents: 129 economics freshmen, 109 economics seniors, 95 sociology freshmen and 118 sociology seniors. Finally, a total of 418 students answered question 2c; of them, 101 were economics freshmen, 94 economics seniors, 116 sociology freshmen and 107 sociology seniors. As previously noted, the four problems are formally identical. Resources are to be distributed between two individuals. Robinson and Friday live on two different islands. Robinson lives on island A and Friday lives on island B. On each island one can till 12 plants. Utility deriving from the goods is increasing and marginal utility is constant. The two characters obtain different levels of utility from the goods, and are only interested in the utility they get.

"The only reason why both Robinson and Friday would like to cultivate these plants 
is because they produce fruit, and the higher amount of fruit they obtain the more their welfare would be; every additional fruit produces an equal value, which is identical for both people."

The respondents are asked to choose a solution among the ones that are provided so that the distribution is just, recalling that there is no possibility of redistributing the plants after the allocation. In question 1 no explanation of the difference between the individuals is provided.

"Friday obtains 120 fruits per year from every plant on island B, but he cannot obtain any fruit from island A's plants.

On both islands Robinson obtains 20 fruits per plant."

In question $2 \mathrm{a}$ and question $2 \mathrm{~b}$ the difference between the individuals is explained. In the former the two individuals differ in their physical abilities, an exogenous difference.

"Both Robinson and Friday put the same amount of work into tilling the plants; the only way to move from one island to the other is to swim.

Friday can obtain 120 fruits per year from every plant of island B, but he cannot swim and he cannot till any plant on island A.

Robinson is a perfect swimmer and he can therefore till plants on both islands, but due to a wound caused by the shipwreck he cannot obtain more than 20 fruits per year from every plant of island A and island B."

In question $2 \mathrm{~b}$ Robinson and Friday put in different efforts in tilling their plants, which is a discretionary difference.

"Robinson and Friday can till plants and move from one island to the other in the same way, but they do not put the same amount of work into tilling the plants.

Friday can obtain 120 fruits per year from every plant of island B, but he doesn't want to go on island $\mathrm{A}$ and he will not produce fruits on this island.

To Robinson moving from one island to the other is all the same, but he does not put as much amount of work into tilling his plants as Friday and he doesn't produce more than 20 fruits per year from every plant, both on island A and B." 4

Question 2c introduces need considerations. No explanation is provided, but a minimum level of utility is introduced.

"The minimum quantity needed by every one of them in order to survive is 300 fruits per year."

\footnotetext{
${ }^{4}$ The idea of the two islands and, in particular, the fact that Friday works harder but does not want to go to the other island is an unnecessary complication, whch we realise could have been avoided. However the answers of the respondents strongly suggest that they were not confused by the design. It does seem reasonable to believe that the results would not be different had the question been simplified.
} 
The distributions are provided in terms of resources as well as in terms of utility; the sum of utility obtained by the individuals is shown too. Three solutions are provided to question $1,2 \mathrm{a}$ and $2 \mathrm{~b}$.

\begin{tabular}{lclcc}
\hline $\mathbf{1}$ & Plants island A & Plants island B & Fruits \\
Robinson & 12 & 0 & 240 \\
Friday & 0 & 12 & 1440 \\
& \multicolumn{2}{c}{ Total production of fruits } & $\mathbf{1 6 8 0}$ & \\
\hline $\mathbf{2}$ & Plants island A & Plants island B & Fruits \\
Robinson & 12 & 8 & 400 \\
Friday & 0 & 4 & 480 \\
& \multicolumn{2}{c}{ Total production of fruits } & $\mathbf{8 8 0}$ & \\
\hline $\mathbf{3}$ & Plants island A & Plants island B & Fruits \\
Robinson & 9 & 9 & & 360 \\
Friday & 3 & 3 & $\mathbf{7 2 0}$ & 360 \\
& \multicolumn{2}{c}{ Total production of fruits } \\
\hline
\end{tabular}

The first solution derives from the application of the utilitarian principle, the second one is the maximin solution, while the third one is the Egalitarian. The Utilitarian solution is the fairest in terms of resources, (R: 12-0; F: 0-12): each individual receives all of the plants of his island. However, this distribution is the most unequal in terms of utility: (R: 240; F: 1440). Social welfare, though, is maximised. The Rawlsian distribution is much more unequal in terms of resources, (R: 12-8; F: 0-4): Robinson receives 8 of the 12 plants of island $\mathrm{B}$, besides the 12 plants of island $\mathrm{A}$. Welfare distribution is much more equal, though, (R: 400; F: 480). The cost of this greater equity is a much lower total welfare. Finally, the Egalitarian distribution gives every individual a utility of 360, distributing the plants as follows: (R: 9-9; F: 3-3). Total welfare is much less than according to the other allocations. Only the Utilitarian and the Rawlsian solutions are Pareto-efficient. Applying the maximin solution both the individuals are better off than under the Egalitarian distribution, which is not Paretoefficient. Besides these distributions a fourth solution ${ }^{5}$, corresponding to utilitarianism with a floor, is provided to question 2c.

$4 \quad$ Plants island A Plants island B Fruits

\footnotetext{
${ }^{5}$ An extension to this study might be the inclusion of the utilitarian solution with a floor in the first three treatments. It would also be interesting to combine the idea of a minimum quantity with the explanations from questions $2 \mathrm{a}$ and $2 \mathrm{~b}$. However, we believe these not to be crucial points of our analysis.
} 


\begin{tabular}{lrrr} 
Robinson & 12 & 3 & 300 \\
Friday & 0 & 9 & 1080 \\
& \multicolumn{2}{c}{ Total production of fruits } & $\mathbf{1 3 8 0}$
\end{tabular}

Plants are divided as follows: (R: 12-3; F: 0-9). Robinson gets 300 fruits, just enough to survive, and Friday gets a utility of 1080 . This distribution is also Pareto-efficient and, in terms of utility, stands between the Rawlsian and the Utilitarian. The latter is the only one that does not guarantee the survival of both the individuals.

We explore five hypotheses.

1. Selection hypothesis. We are interested in testing whether students choosing to study economics and students choosing to study sociology differ in their ideology. In order to test this hypothesis we are going to compare the answers of freshmen of economics and sociology to question 1.

2. Learning hypothesis. We wish to test whether education influences ideology. To test this hypothesis we are going to compare the answers to question 1 given by freshmen and seniors of the same course.

3. Transformation of ideological differences. We are going to test whether ideological differences increase with the seniority of the subjects. This hypothesis will be tested by comparing the answers to question 1 given by senior students of economics and sociology.

4. Relevance of exogenous differences / discretionary differences / need. We are going to test whether contexts affect the preferences of the respondents. We will consider each class separately and test the hypothesis of no change in the answer to the first and the second question.

5. Agreement hypothesis. Finally, we will compare the answers of the four groups to questions $2 \mathrm{a}, 2 \mathrm{~b}$ and $2 \mathrm{c}$, and test whether clarifying the context or introducing a minimum utility allows reaching an agreement between the groups.

\section{Results}

In presenting our results we will proceed as follows. First, we will focus on the difference between economics and sociology students, testing the selection and learning hypotheses. Then, we will analyse the effects of clarifying the context of the distribution and the extent to which this facilitates an agreement between the parties. ${ }^{6}$

\footnotetext{
${ }^{6}$ Before proceeding to test the above hypotheses we have to make sure that in each group the three different versions of the questionnaire have been randomly distributed among the respondents. For each group, we have to check that the answers to the first question follow the same distribution in everyone of the three classes. For each one of the four groups, we apply the Chi-square test to test the
} 


\subsection{Ideology}

Table 1 reports the answers to question 1. In the tables and figures we will present, E, R, U and UF indicate, respectively, Egalitarian, Rawlsian, Utilitarian and Utilitarian with a floor.

Table 1. Question 1 (Percentage responses)

\begin{tabular}{lllll}
\hline \hline Solutions & $\begin{array}{c}\text { Economics } \\
\text { Freshmen }\end{array}$ & $\begin{array}{c}\text { Economics } \\
\text { Seniors }\end{array}$ & $\begin{array}{c}\text { Sociology } \\
\text { Freshmen }\end{array}$ & $\begin{array}{c}\text { Sociology } \\
\text { Seniors }\end{array}$ \\
\hline $\mathrm{E}$ & 35 & 22 & 47 & 47 \\
$\mathrm{R}$ & 38 & 50 & 37 & 34 \\
$\mathrm{U}$ & 27 & 28 & 16 & 19 \\
\hline \hline
\end{tabular}

Let us consider the answers to question 1 given by the freshmen of economics and sociology first. This will allow us to test the selection hypothesis. We can easily notice a consistent difference between the two distributions, the preferences of the economics students being more equally distributed between the three options. In both the groups there are a similar percentage of subjects choosing the Rawlsian principle, 38 percent of the economics students and 37 percent of the sociology ones. However, while 47 percent of the sociologists prefer the Egalitarian solution and only 16 percent the Utilitarian, these percentages are much closer among the economists, respectively 35 percent and 27 percent.

\section{Selection hypothesis}

$$
\begin{aligned}
H_{0}: & \text { the choice of a particular option } \\
& \text { is unrelated to the university course. }
\end{aligned}
$$

Given the value of the test statistic, $\chi^{2}=15.57$, we reject the null hypothesis $(p=$ 0.0004). This leads to the following result.

Result 1: A selection effect does exist. Sociology students are more concerned with equality than economics students and prefer the Egalitarian distribution despite its inefficiency.

following hypothesis

$$
\begin{array}{r}
H_{0}: \text { the proportion of subjects in each of the option } \\
\text { categories is the same in each of the three classes. }
\end{array}
$$

The value of the test statistic is $\chi^{2}=0.55$ for economics freshmen $(p=0.9685), \chi^{2}=3.38$ for economics seniors $(p=0.4963), \chi^{2}=0.72$ for sociology freshmen $(p=0.9488)$ and $\chi^{2}=2.98$ for sociology seniors $(p=0.5612)$. For every group we cannot reject the null hypothesis. This allows us to proceed to any type of inferential analysis of the data and to test the hypotheses presented above. 


\subsection{Education: Equity and Efficiency}

We are going to analyse whether education influences ideology by comparing the answers to question 1 given by freshmen and seniors of the same discipline. Table 1 shows that the answers of the economics seniors are much more differentiated than those of their younger colleagues. The percentage of preferences for the Utilitarian allocation is almost identical in both the groups (27 percent among the freshmen and 28 percent among the seniors). However the preferences for the Egalitarian distribution diminish from the freshmen (35 percent) to the seniors (22 percent) to the advantage of the maximin principle. On the other hand, interestingly, we notice that the distributions of preferences of sociology freshmen and seniors are almost identical.

\section{Learning hypothesis}

$$
\begin{aligned}
H_{0}: & \text { the choice of a particular option is } \\
& \text { unrelated to the university year. }
\end{aligned}
$$

We reject the null hypothesis $(p=0.0003)$ with respect to the economics students $\left(\chi^{2}=15.88\right)$, but we cannot reject it $(p=0.61569)$ for the sociology ones $\left(\chi^{2}=0.97\right)$. This leads to the next result.

Result 2: A learning effect only exists for the economics students. The Egalitarian solution is less popular with economics seniors, who instead prefer the Rawlsian distribution.

Unlike Carter and Irons (1991), we can therefore conclude that economists are not only born, but also made. Our results also seem to contradict the results obtained by Frank, Gilovich, and Regan (1993). They found that economics students appear to be more prone than others to defect, that is to go for the Pareto-inferior solution, and this trend increases with the seniority of the subjects. They claimed that training in economics has, amongst others, negative consequences, i.e. anti-social behaviour (Frank, Gilovich, and Regan, 1996). Our results indicate the presence of a learning effect that reflects an increasing appreciation for the maximin principle. The latter does satisfy the Pareto criterion ${ }^{7}$, which is not the case for the Egalitarian distribution. However, the shift in preferences is not at all in the direction of the Utilitarian solution, which suggests that senior students are no more concerned with the maximisation of output than their younger colleagues. Given that senior students of economics are more likely to favour inequality only if this implies making both the individuals better off, training in economics does not seem to have negative consequences.

However, we have to bear in mind the differences between the experiments we discussed in Section 3 and our study. Carter and Irons (1991) and Frank and his colleagues

\footnotetext{
${ }^{7}$ It is interesting to notice that several studies show that the Pareto principle is not a very popular concept with economics and business students (e.g. McClelland and Rohrbaugh, 1978; Amiel and Cowell, 1999). However, non-economists seem to believe in it even less (Amiel and Cowell, 1999).
} 
(1993) were interested in finding whether exposure to the rational model of economics makes subjects behave in a more self-interested way. Our approach differs in two ways. First, we concentrate our analysis on the perception of fairness of the subjects rather than on their behaviour. Second, self-interest bias is drastically reduced by the elimination of monetary incentives ${ }^{8}$.

\subsection{Does Education Increase Ideological Differences?}

We want to check whether ideological differences between the students of the two courses increase with the different education or remain stable. Looking at Table 1 we can see that the difference between the two distributions seems to have increased from the first to the last year. Let us test the hypothesis of transformation of ideological differences. The null hypothesis is the same as hypothesis (1). The value of the test statistic is $\chi^{2}=44.5$ and we reject the null hypothesis $(p=2.177 \mathrm{e}-10)$. Moreover, the Cramer coefficient $^{9}$ shows that the ideological difference between the seniors of the two courses is much greater than between their younger colleagues.

Result 3: The ideological difference between senior students of economics and sociology is greater than between the freshmen of the two courses.

\subsection{The Impact of Context}

Table 2 reports the answers to the three different versions of question 2 .

\begin{tabular}{llllll}
\multicolumn{6}{c}{ Table 2. Question 2a $/ 2 b / 2 c$ (Percentage responses) } \\
\hline \hline \multirow{2}{*}{ Questions } & Solutions & $\begin{array}{c}\text { Economics } \\
\text { Freshmen }\end{array}$ & $\begin{array}{c}\text { Economics } \\
\text { Seniors }\end{array}$ & $\begin{array}{c}\text { Sociology } \\
\text { Freshmen }\end{array}$ & $\begin{array}{c}\text { Sociology } \\
\text { Seniors }\end{array}$ \\
\hline $2 \mathrm{a}$ & $\mathrm{E}$ & 15 & 7 & 25 & 32 \\
& $\mathrm{R}$ & 63 & 76 & 60 & 60 \\
& $\mathrm{U}$ & 22 & 17 & 15 & 8 \\
\hline $\mathrm{2b}$ & $\mathrm{E}$ & 12 & 6 & 13 & 14 \\
& $\mathrm{R}$ & 34 & 28 & 38 & 36 \\
& $\mathrm{U}$ & 54 & 66 & 49 & 50 \\
\hline $\mathrm{2c}$ & $\mathrm{E}$ & 30 & 19 & 41 & 36 \\
& $\mathrm{R}$ & 41 & 44 & 44 & 32 \\
& $\mathrm{U}$ & 4 & 1 & 0 & 3 \\
& $\mathrm{UF}$ & 26 & 36 & 15 & 30 \\
\hline \hline
\end{tabular}

\footnotetext{
${ }^{8}$ Note that self-interest bias cannot be completely eliminated. Although the respondents have to divide the resources between two hypothetical individuals, they might still act as vicarious stakeholders.

${ }^{9}$ The Cramer coefficient measures the degree of relation between two sets of variables. The value of this coefficient almost doubles passing from the freshermen's sample to the seniors' one, from 0.15 to 0.27 , indicating a much stronger relation between the preferences of the senior students and the course attended.
} 
Unlike the base version, in the exogenous difference treatment the absolute majority of each group prefer the Rawlsian solution. This trend can be understood if we consider that both the individuals exert the same effort, but they differ in their physical abilities, a characteristic they cannot be held responsible for. Maximising the utility of the more disadvantaged is considered fair by most of the individuals, whatever group they belong to.

In the case of discretionary differences, the Utilitarian solution is the most preferred by each one of the four groups. This result is even more striking considering that utilitarianism was the least preferred solution to the first problem by three of the four groups and only the second choice of the economics seniors. The two individuals are held accountable for their outcomes when they differ in their effort. The Utilitarian solution, which rewards the character that puts in more effort, is preferred to the other allocations in each group. The answers to this problem are even more homogenous then those to question 2a. The four classes present the same order of preferences: the maximin solution is the second choice, followed by the Egalitarian.

Need seems the most obvious force driving the results on question 2c. Economics freshmen and seniors and sociology freshmen prefer the maximin solution, while among the sociology seniors egalitarianism is still the first choice. The four groups share the same scepticism for the Utilitarian solution, which does not guarantee the survival of the more disadvantage individual. Egalitarianism still proves to be more appreciated by the sociology students; however, even among them, the preferences for the Egalitarian solution decrease from freshmen to seniors in favour of utilitarianism with a floor. The latter seems to exert a particular attraction on more mature students, whatever course they attend.

In order to analyse the relevance of context we are going to compare the answers given by each student to the first and the second question, anlysing first problem $2 \mathrm{a}$ and $2 \mathrm{~b}$ and then problem $2 \mathrm{c}$. The results of all the tests of differences are reported in Appendix B.

Concerning those subjects who received question $2 \mathrm{a}$ and those who received question $2 \mathrm{~b}$, we can test the significance of the change in their by applying the Stuart-Maxwell test $^{10}$.

Relevance of exogenous / discretionary differences

$$
\begin{aligned}
H_{0}: \text { there is no change in the preferences of the } \\
\text { subjects passing from the first to the second problem. }
\end{aligned}
$$

In each case we can reject the null hypothesis. This leads to the following result:

Result 4: Introducing either exogenous or discretionary differences has changed the preferences of the subjects, whatever group they belong to.

\footnotetext{
${ }^{10}$ The Stuart-Maxwell test is a variation of McNemar's test appropriate for case-control comparisons involving $3 \times 3$ contingency tables. It can be used to test marginal homogeneity between two raters across all categories simultaneously ( for a general discussion see Fleiss, 1981).
} 
With reference to both classes of each of the four groups, we can look for those single categories for which the differences are significant. We can collapse the original $3 \times 3$ tables into $2 \times 2$ tables $^{11}$ and apply the McNemar test to three different hypotheses.

$$
\begin{aligned}
H_{0}: & \text { among the respondents who change their } \\
& \text { preference, the probability that a respondent } \\
& \text { will switch from } \mathrm{E}(\mathrm{R} / \mathrm{U}) \text { to not } \mathrm{E} \text { (not } \mathrm{R} / \\
& \text { not } \mathrm{U} \text { ) will be the same as the probability that } \\
& \text { a respondent will change from not } \mathrm{E} \text { (not } \mathrm{R} / \\
& \text { not } \mathrm{U} \text { ) to } \mathrm{E}(\mathrm{R} / \mathrm{U}) \text {. }
\end{aligned}
$$

In the case of exogenous differences, for each of the four groups we reject the null hypothesis concerning the Egalitarian and the maximin allocation. Once it is explained that the lower productivity of one of the two characters is due to a handicap the consent for the Egalitarian solution diminishes, while more subjects are in favour of the Rawlsian allocation. Furthermore, considering the economics seniors, we can also reject the null hypothesis concerning the Utilitarian distribution, which is preferred by fewer subjects as a solution to problem $2 \mathrm{a}$.

Result 5: With the introduction of exogenous differences, the preferences of each group for the Egalitarian distribution have decreased in favour of the maximin solution. The preferences of the economics seniors for both the Egalitarian and Utilitarian solutions have diminished in favour of the maximin one.

Let us consider the discretionary difference treatment. For each of the four groups we reject the null hypothesis concerning the Egalitarian and Utilitarian solutions. When the different productivity is explained in terms of effort the preferences for the Egalitarian distribution decrease, while more people prefer the Utilitarian allocation. Considering the economics seniors, we reject the null concerning each of the three options: the preferences for the maximin and the Egalitarian distribution diminish from the first to the second problem, in favour of the Utilitarian allocation.

Result 6: With the introduction of discretionary differences, the preferences of each group for the Egalitarian distribution have decreased in favour of the Utilitarian solution. The preferences of the economics seniors for both the Egalitarian and maximin solutions have diminished in favour of the Utilitarian one.

As revealed by these results, passing from the first to the second question has significantly lowered the consent for the Egalitarian solution among all the groups. This leads to an important result:

\footnotetext{
${ }^{11}$ In these $2 \times 2$ tables the answers to the first and to the second question will be categorised respectively as Egalitarian and not Egalitarian, Rawlsian and not Rawlsian, Utilitarian and not Utilitarian.
} 
Result 7: The inefficient allocation seems to be an inadequate solution to the problem, once the circumstances of the distribution are clear.

Let us finally test hypothesis of relevance of need with respect to the subjects who received question $2 \mathrm{c}^{12}$. For each group we can reject the null hypothesis with reference to the Utilitarian solution. Need considerations have driven the preferences for the latter to drastically fall in every group. In addition, considering the senior students we reject the null concerning two other mechanisms: the egalitarian with respect to the sociology seniors, and the maximin with reference to the seniors of economics. The two groups show much less consent for these principles when answering question 2c.

Result 8: With the introduction of a threshold, the preferences of each group for the Utilitarian distribution have drastically fallen. Moreover, the preferences of the sociology seniors for the Egalitarian allocation have decreased, while the maximin solution is preferred by fewer economics seniors.

From Figures 1 and 2 we can intuitively infer that when either exogenous or discretionary differences are introduced the answers of the four groups are much more similar.

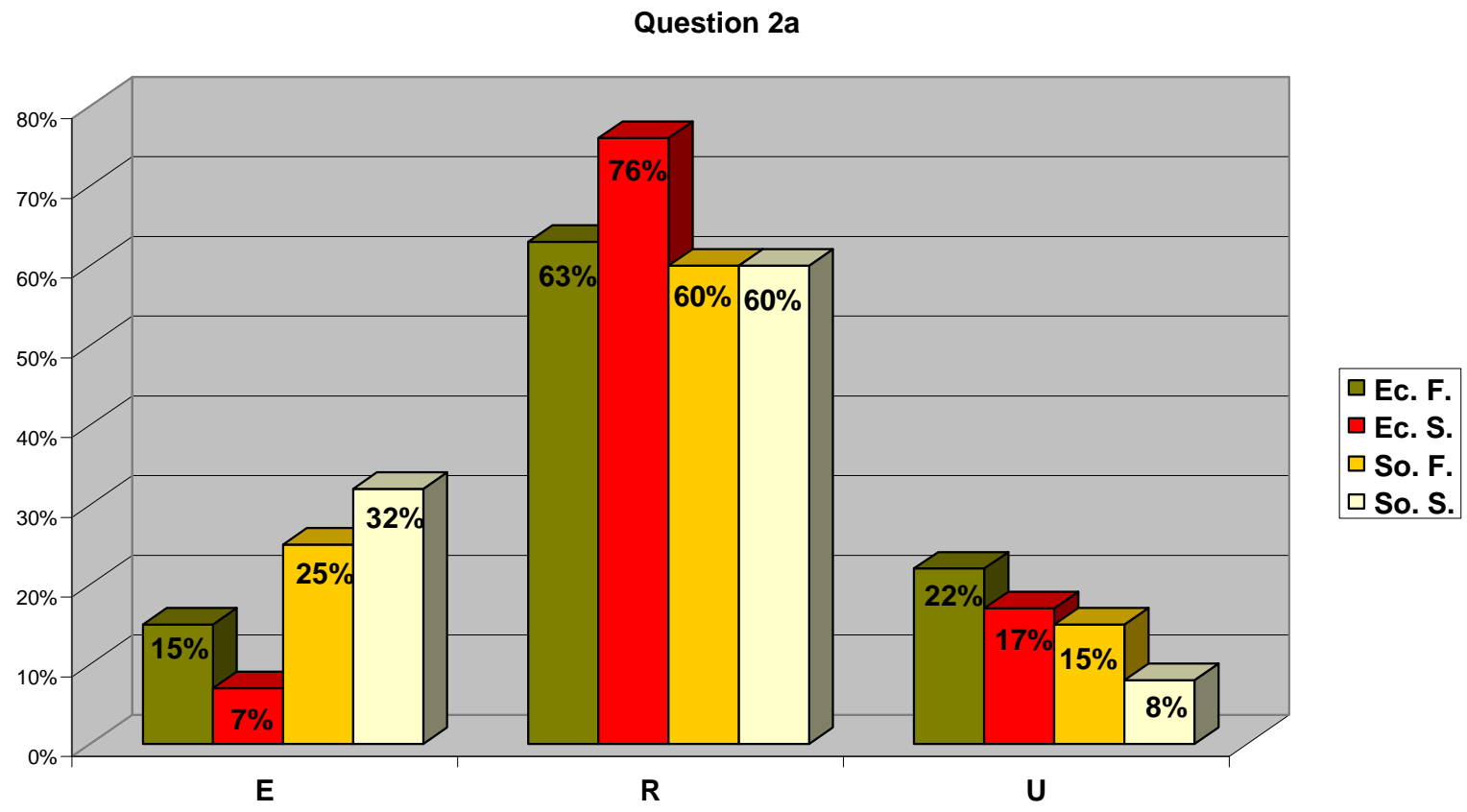

Figure 1

\footnotetext{
${ }^{12}$ While the first problem presents three solutions, four distinct distributions are provided as possible solutions to question 2c. The Stuart-Maxwell test cannot be used to test marginal homogeneity in this case and, furthermore, no appropriate test for case-control comparisons involving $3 \mathrm{x} 4$ contingency tables exists. It will only be possible to test (4) by applying the McNemar test.
} 


\section{Question 2b}

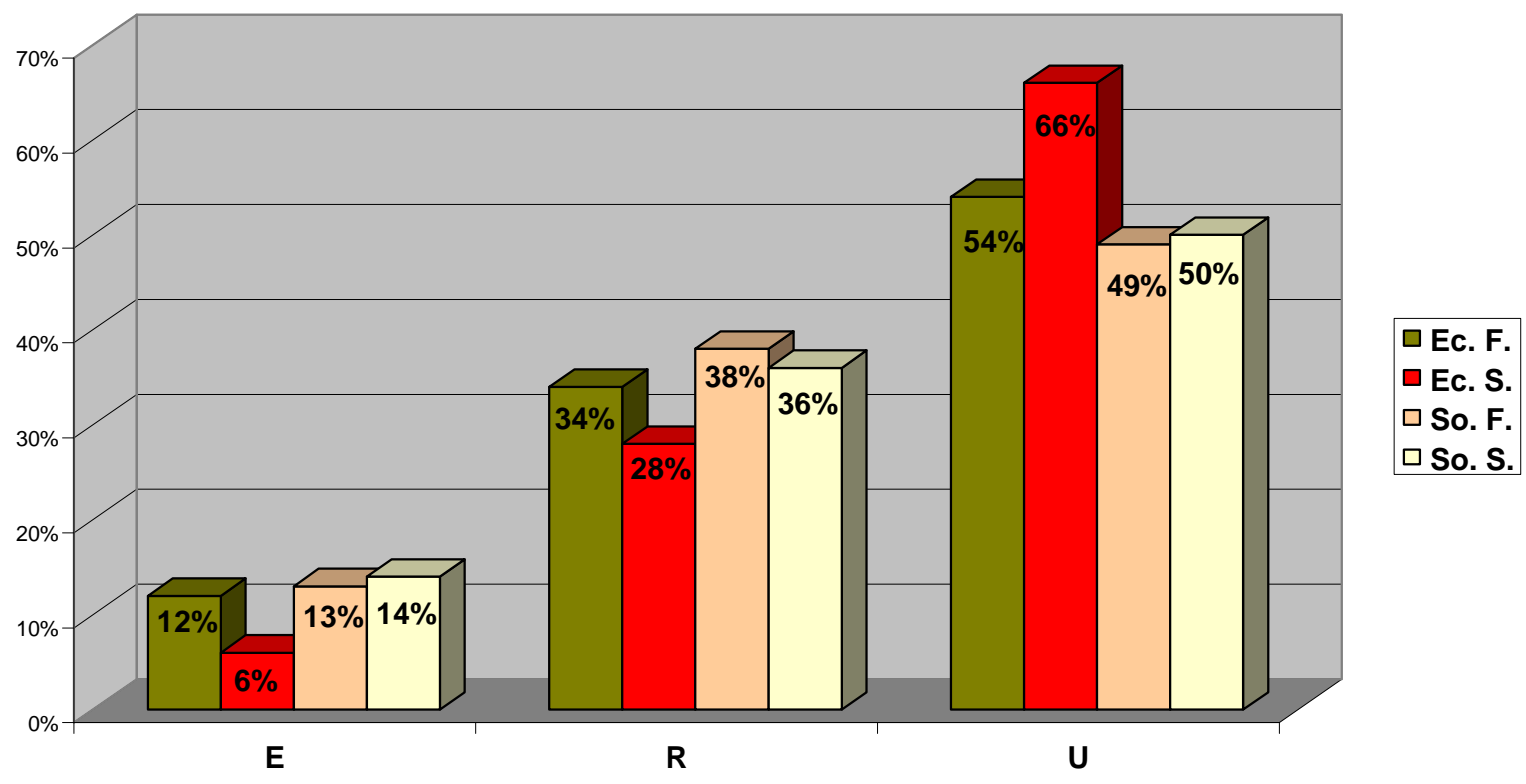

Figure 2

Let us conclude our analysis investigating whether clarifying the context of the distribution leads to a common solution accepted by the parties.

\section{Agreement hypothesis}

$$
\begin{aligned}
H_{0}: & \text { the proportion of subjects in each of } \\
& \text { the option categories is the same in } \\
& \text { each group }
\end{aligned}
$$

Let us first consider the case of exogenous differences. The value of the test statistic is $\chi^{2}=29.21$ and we reject the null hypothesis $(p=0.00005)$ : although in each of the four groups the absolute majority prefer the Rawlsian solution, the preferences of the four groups do not follow the same distribution. We can test hypothesis (5) with reference to four different cases: economics and sociology freshmen, economics and sociology seniors, economics freshmen and seniors, sociology freshmen and seniors. We reject the null $(p=0.00001)$ only concerning economics and sociology seniors, given the high Chi-square value, $\chi^{2}=22.9$. We cannot reject it in the other cases. Testing the hypothesis with economics and sociology freshmen we have $\chi^{2}=4.49(p=0.1059)$. Testing it with economics freshmen and seniors the Chi-square value is $\chi^{2}=5.68(p$ $=0.0584)$. In the case of sociology freshmen and seniors the result is $\chi^{2}=3.39(p=$ 0.1836). Let us make two interesting points. First, contrary to the answers to question 1 , we cannot reject the hypothesis that the preferences of economics and sociology 
freshmen follow the same distribution. Second, we cannot reject the hypothesis of no difference between the preferences of economics freshmen and seniors. Let us summarise these results.

Result 9: When exogenous differences are introduced, the absolute majority of every group prefer the maximin principle as a solution to the problem. In addition, the difference due to the selection effect as well as the disagreement between economics freshmen and seniors has disappeared.

In the case of discretionary differences, testing hypothesis (5) with respect to all the groups the value of the test statistic is $\chi^{2}=8.5$. We cannot reject the hypothesis according to which the preferences of the four groups follow the same distribution $(p=$ $0.2037)$.

Result 10: The preferences of the four groups with respect to the problem with discretionary differences follow the same distribution. The Utilitarian allocation is the most preferred, the maximin solution is the second choice and the Egalitarian is the least preferred.

Finally, we consider the need version of the distribution problem. Testing hypothesis (5) with reference to the four groups the value of the test statistic is $\chi^{2}=26.5$ and we have to reject the null hypothesis $(p=0.0017)$. The only case in which we cannot reject it $(p=0.1316)$ is comparing the answers of the economics freshmen and seniors, $\chi^{2}=5.62$. With respect to them, we can conclude that their preferences follow the same distribution. Unlike other experiments (Frohlich, Oppenheimer, and Eavy, 1987a, 1987b; Lissowsky, Tyszka, and Okrasa, 1991), the introduction of a floor did not enable a solution accepted by all of the parties. However, we notice that an agreement looks closer now than in the first problem. Three groups prefer the Rawlsian solution and even among the sociology seniors the percentage of preferences for the maximin allocation is very close to the first choice. The solution we proposed according to utilitarianism with a floor only guarantees the survival of the least advantaged character. That did not look enough to most of the subjects, who instead preferred maximising his utility. An interesting extension would be to test whether solutions with an intermediate floor would lead to greater consensus. The following summarises these results.

Result 11: In the need treatment all of the groups, except for the sociology seniors, prefer the maximin allocation as a solution to the question, while the utilitarian distribution is by far the least preferred by each group. Utilitarianism with a floor is more preferred by senior students.

\section{Conclusions}

Several studies have been conducted to analyse whether judgments of fairness are context dependent. To our knowledge, though, this is the first attempt to explore distribu- 
tive justice analysing the extent to which clarifying the context of a distribution favours greater consensus on what is just. We surveyed first and last year undergraduate students of economics and sociology, focusing on contextual factors related to responsibility and need considerations. Let us summarise the main results we obtained.

A selection effect does exist. The ideology of students choosing to study sociology differs from that of students who choose to study economics, the former group being much more concerned about equality. Further, the differences in ideology increase with the seniority of the subjects. Economics seniors show a higher appreciation of the Pareto principle than their younger colleagues, which is not the case with sociology students (with reference to this point see also Amiel and Cowell, 1999, although the authors do not distinguish between selection and learning effects). However, training in economics does not seem to influence the concern for the maximisation of total output. These results cannot be directly compared to most of the literature about the differences between economists and non-economists, these studies being aimed to analyse whether students of economics behave in a more self-interested way than students of other disciplines. In any case, unlike the results obtained by Marwell and Ames (1981), our results indicate that even economics students have an interest in fairness. This may be due to the different design of the question.

Clarifying the context of the distribution, by either explaining the differences between the individuals or introducing a minimum survival utility, significantly influences perception of fairness of the subjects, whatever group they belong to. Whenever it is not efficient, the egalitarian principle seems to provide inadequate solutions if the circumstances of the distributions are clear. Need considerations seem to drive the results when a floor is introduced: the utilitarian principle is abandoned, if the solution it prescribes does not enable every individual to reach the minimum utility. Interestingly sociology seniors develop an increased preference for utilitarianism with a floor relative to sociology freshmen.

The most notable result is that clarifying the context favours greater consensus on what is fair. The maximin criterion proves to be an adequate solution to the distribution problem when exogenous differences, for which the individuals cannot be held responsible, are introduced. The utilitarian principle, on the contrary, meets a great success when the individuals put in different efforts (discretionary differences). The introduction of a floor does not seem to be an equally successful way to achieve a social agreement. However, only a particular solution corresponding to the utilitarian principle with a floor constraint has been explored. There are several interesting extensions for future research and a series of social experiments should be conducted in order to point out a plausible threshold that would appear just to most people. 


\section{Appendix A}

\section{Question 1}

After a shipwreck Robinson and Friday have landed on two different islands divided by a narrow but deep channel.

On each of the two islands one can till 12 plants. The only reason why both Robinson and Friday would like to cultivate these plants is because they produce fruit and the higher amount of fruit they obtain, the more their welfare would be; every additional fruit produces an equal value, which is identical for both people.

It has been decided that you are the one who will chose how to distribute the plants between Robinson and Friday. You've been given the following information, which the two survivors also know:

Robinson lives on island $\mathbf{A}$ and Friday lives on island $\mathbf{B}$.

All plants of one island are identical to the ones of the other island. How much fruit they produce depends on the way they are cultivated.

Friday obtains 120 fruits per year from every plant on island B, but he cannot obtain any fruit from island A's plants.

On both islands Robinson obtains 20 fruits per plant.

There's no possibility of redistributing the plants after the allocation and there's also no chance to exchange any fruit, which is produced.

How would you divide the 12 plants of island A and the 12 plants of island $\mathrm{B}$ so that, from your point of view, the distribution would be just?

Choose:

\begin{tabular}{lclcc}
\hline $\mathbf{1}$ & Plants island A & Plants island B & Fruits \\
Robinson & 12 & 0 & 240 \\
Friday & 0 & 12 & 1440 \\
& \multicolumn{2}{c}{ Total production of fruits } & $\mathbf{1 6 8 0}$ & \\
\hline $\mathbf{2}$ & Plants island A & Plants island B & Fruits \\
Robinson & 12 & 8 & 400 \\
Friday & 0 & 4 & 480 \\
& \multicolumn{2}{c}{ Total production of fruits } & $\mathbf{8 8 0}$ & \\
\hline $\mathbf{3}$ & Plants island A & Plants island B & Fruits \\
Robinson & 9 & 9 & & 360 \\
Friday & 3 & 3 & $\mathbf{7 2 0}$ & 360 \\
& \multicolumn{2}{c}{ Total production of fruits } \\
\hline
\end{tabular}

\section{Question 2a}


After a shipwreck Robinson and Friday have landed on two different islands divided by a narrow but deep channel.

On each of the two islands one can till 12 plants. The only reason why both Robinson and Friday would like to cultivate these plants is because they produce fruit and the higher amount of fruit they obtain, the more their welfare would be; every additional fruit produces an equal value, which is identical for both people.

It has been decided that you are the one who will chose how to distribute the plants between Robinson and Friday.

You've been given the following information, which the two survivors also know:

Robinson lives on island $\mathbf{A}$ and Friday lives on island $\mathbf{B}$.

All plants of one island are identical to the ones of the other island. How much fruit they produce depends on the way they are cultivated.

Both Robinson and Friday put the same amount of work into tilling the plants; the only way to move from one island to the other is to swim.

Friday can obtain $\mathbf{1 2 0}$ fruits per year from every plant of island B, but he cannot swim and he cannot till any plant on island A.

Robinson is a perfect swimmer and he can therefore till plants on both islands, but due to a wound caused by the shipwreck he cannot obtain more than 20 fruits per year from every plant of island A and island B.

There's no possibility of redistributing the plants after the allocation and there's also no chance to exchange any fruit, which is produced.

How would you divide the 12 plants of island A and the 12 plants of island B so that, from your point of view, the distribution would be just?

Choose:

\begin{tabular}{|c|c|c|c|}
\hline 1 & Plants island A & Plants island B & Fruits \\
\hline Robinson & 12 & 0 & 240 \\
\hline \multirow[t]{2}{*}{ Friday } & 0 & 12 & 1440 \\
\hline & \multicolumn{2}{|c|}{ Total production of fruits } & \\
\hline 2 & Plants island $\mathrm{A}$ & Plants island B & Fruits \\
\hline Robinson & 12 & 8 & 400 \\
\hline \multirow[t]{2}{*}{ Friday } & 0 & 4 & 480 \\
\hline & \multicolumn{2}{|c|}{ Total production of fruits } & \\
\hline 3 & Plants island $\mathrm{A}$ & Plants island B & Fruits \\
\hline Robinson & 9 & 9 & 360 \\
\hline \multirow[t]{2}{*}{ Friday } & 3 & 3 & 360 \\
\hline & \multicolumn{2}{|c|}{ Total production of fruits } & \\
\hline
\end{tabular}




\section{Question 2b}

After a shipwreck Robinson and Friday have landed on two different islands divided by a narrow but deep channel.

On each of the two islands one can till 12 plants. The only reason why both Robinson and Friday would like to cultivate these plants is because they produce fruit and the higher amount of fruit they obtain, the more their welfare would be; every additional fruit produces an equal value, which is identical for both people.

It has been decided that you are the one who will chose how to distribute the plants between Robinson and Friday.

You've been given the following information, which the two survivors also know:

Robinson lives on island $\mathbf{A}$ and Friday lives on island $\mathbf{B}$.

All plants of one island are identical to the ones of the other island. How much fruit they produce depends on the way they are cultivated.

Robinson and Friday can till plants and move from one island to the other in the same way, but they do not put the same amount of work into tilling the plants.

Friday can obtain 120 fruits per year from every plant of island B, but he doesn't want to go on island A and he will not produce fruits on this island.

To Robinson moving from one island to the other is all the same, but he does not put as much amount of work into tilling his plants as Friday and he doesn't produce more than 20 fruits per year from every plant, both on island A and B.

There's no possibility of redistributing the plants after the allocation and there's also no chance to exchange any fruit, which is produced.

How would you divide the 12 plants of island A and the 12 plants of island B so that, from your point of view, the distribution would be just?

Choose:

\begin{tabular}{|c|c|c|c|}
\hline 1 & Plants island A & Plants island B & Fruits \\
\hline Robinson & 12 & 0 & 240 \\
\hline \multirow[t]{2}{*}{ Friday } & 0 & 12 & 1440 \\
\hline & \multicolumn{2}{|c|}{ Total production of fruits } & \\
\hline 2 & Plants island A & Plants island B & Fruits \\
\hline Robinson & 12 & 8 & 400 \\
\hline \multirow[t]{2}{*}{ Friday } & 0 & 4 & 480 \\
\hline & \multicolumn{2}{|c|}{ Total production of fruits } & \\
\hline 3 & Plants island A & Plants island B & Fruits \\
\hline Robinson & 9 & 9 & 360 \\
\hline Friday & 3 & 3 & 360 \\
\hline
\end{tabular}




\section{Question 2c}

After a shipwreck Robinson and Friday have landed on two different islands divided by a narrow but deep channel.

On each of the two islands one can till 12 plants. The only reason why both Robinson and Friday would like to cultivate these plants is because they produce fruit and the higher amount of fruit they obtain, the more their welfare would be; every additional fruit produces an equal value, which is identical for both people.

It has been decided that you are the one who will chose how to distribute the plants between Robinson and Friday.

You've been given the following information, which the two survivors also know:

The minimum quantity needed by every one of them in order to survive is $\mathbf{3 0 0}$ fruits per year.

Robinson lives on island $\mathbf{A}$ and Friday lives on island $\mathbf{B}$

All plants of one island are identical to the ones of the other island. How much fruit they produce depends on the way they are cultivated.

Friday obtains $\mathbf{1 2 0}$ fruits per year from every plant on island B, but he cannot obtain any fruit from island A's plants.

On both islands Robinson obtains 20 fruits per plant.

There's no possibility of redistributing the plants after the allocation and there's also no chance to exchange any fruit, which is produced.

How would you divide the 12 plants of island A and the 12 plants of island B so that, from your point of view, the distribution would be just?

Choose:

\begin{tabular}{|c|c|c|c|c|}
\hline \multirow{4}{*}{$\begin{array}{l}1 \\
\text { Robinson } \\
\text { Friday }\end{array}$} & Plants island A & \multicolumn{2}{|c|}{ Plants island B } & Fruits \\
\hline & 12 & 0 & & 240 \\
\hline & 0 & 12 & & 1440 \\
\hline & \multicolumn{2}{|c|}{ Total production of fruits } & \multicolumn{2}{|c|}{1680} \\
\hline 2 & Plants island A & Plants isl & & Fruits \\
\hline Robinson & 12 & 8 & & 400 \\
\hline \multirow[t]{2}{*}{ Friday } & 0 & 4 & & 480 \\
\hline & \multicolumn{2}{|c|}{ Total production of fruits } & \multicolumn{2}{|c|}{880} \\
\hline 3 & Plants island A & Plants isl & & Fruits \\
\hline Robinson & 9 & 9 & & 360 \\
\hline Friday & 3 & 3 & & 360 \\
\hline
\end{tabular}


Total production of fruits

720

\begin{tabular}{lccr}
\hline $\mathbf{4}$ & Plants island A & Plants island B & Fruits \\
Robinson & 12 & 3 & 300 \\
Friday & 0 & 9 & 1080 \\
& \multicolumn{2}{c}{ Total production of fruits } & $\mathbf{1 3 8 0}$ \\
\end{tabular}

\section{Appendix B}

We report the Chi-square values resulting from testing hypotheses (3) and (4). The numbers in brackets represent the p-values.

Table 3 reports the results of the application of the Stuart-Maxwell tests to hypothesis (3).

\begin{tabular}{lcccc}
\multicolumn{5}{c}{ Table 3. Stuart-Maxwell tests } \\
\hline \hline & Economics & Economics & Sociology & Sociology \\
& Freshmen & Seniors & Freshmen & Seniors \\
\hline \multirow{2}{*}{ Question 1/2a } & 19.8 & 21.89 & 20.21 & 19.53 \\
& $(0.0005)$ & $(0.0002)$ & $(0.0004)$ & $(0.0006)$ \\
Question 1/2b & 25.32 & 35.36 & 40.65 & 48.17 \\
& $(0.00004)$ & $(3.918 \mathrm{e}-7)$ & $(3.176 \mathrm{e}-8)$ & $(8.698 \mathrm{e}-10)$ \\
\hline \hline
\end{tabular}

The following tables report the results of the application of the McNemar tests to hypothesis (4) with respect to economics freshmen, economics seniors, sociology freshmen and sociology seniors.

\begin{tabular}{cccc}
\multicolumn{4}{c}{ Table 4. Economics Freshmen (McNemar tests) } \\
\hline \hline & $\mathrm{E} /$ not E & $\mathrm{R} /$ not R & $\mathrm{U} /$ not U \\
\hline \multirow{2}{*}{ Question 1/2a } & 14.38 & 15.8 & 0.24 \\
& $(0.0001)$ & $(0.00007)$ & $(0.6242)$ \\
Question 1/2b & 16.68 & 0.5 & 19.59 \\
& $(0.0004)$ & $(0.4795)$ & $(9.597 \mathrm{e}-06)$ \\
Question 1/2c & 0.45 & 0.11 & 19.05 \\
& $(0.5023)$ & $(0.7401)$ & $(0.00001)$ \\
\hline \hline
\end{tabular}




\begin{tabular}{|c|c|c|c|}
\hline & $\mathrm{E} / \operatorname{not} \mathrm{E}$ & $\mathrm{R} / \operatorname{not} \mathrm{R}$ & $\mathrm{U} / \operatorname{not} \mathrm{U}$ \\
\hline Question 1/2a & $\begin{array}{c}8.45 \\
(0.0036)\end{array}$ & $\begin{array}{c}20.1 \\
(7.350 \mathrm{e}-6)\end{array}$ & $\begin{array}{c}7.26 \\
(0.0070)\end{array}$ \\
\hline Question 1/2b & $\begin{array}{c}12 \\
(0.0005)\end{array}$ & $\begin{array}{c}8.76 \\
(0.0031)\end{array}$ & $\begin{array}{c}32.59 \\
(1.138 \mathrm{e}-8)\end{array}$ \\
\hline Question 1/2c & $\begin{array}{c}0.36 \\
(0.5485)\end{array}$ & $\begin{array}{c}5.26 \\
(0.0218)\end{array}$ & $\begin{array}{c}18.05 \\
(0.00002) \\
\end{array}$ \\
\hline \multicolumn{4}{|c|}{ Table 6. Sociology Freshmen (McNemar tests) } \\
\hline & $\mathrm{E} / \operatorname{not} \mathrm{E}$ & R / not R & $\mathrm{U} / \operatorname{not} \mathrm{U}$ \\
\hline Question 1/2a & $\begin{array}{c}17.42 \\
(0.00002)\end{array}$ & $\begin{array}{c}16.17 \\
(0.00005)\end{array}$ & $\begin{array}{c}0 \\
(1)\end{array}$ \\
\hline Question $1 / 2 b$ & $\begin{array}{c}27.84 \\
(1.318 \mathrm{e}-7\end{array}$ & $\begin{array}{c}0.21 \\
(0.6468)\end{array}$ & $\begin{array}{c}28.26 \\
(1.061 \mathrm{e}-7)\end{array}$ \\
\hline Question 1/2c & $\begin{array}{c}1.07 \\
(0.3009) \\
\end{array}$ & $\begin{array}{c}2.23 \\
(0.1353)\end{array}$ & $\begin{array}{c}18.05 \\
(0.0002) \\
\end{array}$ \\
\hline & $\mathrm{E} / \operatorname{not} \mathrm{E}$ & $\mathrm{R} / \operatorname{not} \mathrm{R}$ & $\mathrm{U} / \operatorname{not} \mathrm{U}$ \\
\hline Question 1/2a & $\begin{array}{c}9.48 \\
(0.0021)\end{array}$ & $\begin{array}{c}16.96 \\
(0.00003)\end{array}$ & $\begin{array}{c}2.28 \\
(0.1310)\end{array}$ \\
\hline Question 1/2b & $\begin{array}{c}30.62 \\
(3.138 \mathrm{e}-8)\end{array}$ & $\begin{array}{c}0.08 \\
(0.7773)\end{array}$ & $\begin{array}{c}31.03 \\
(2.541 \mathrm{e}-8)\end{array}$ \\
\hline Question $1 / 2 \mathrm{c}$ & $\begin{array}{c}7.56 \\
(0.0060) \\
\end{array}$ & $\begin{array}{c}0 \\
(1) \\
\end{array}$ & $\begin{array}{c}17.05 \\
(0.0003) \\
\end{array}$ \\
\hline
\end{tabular}

\section{References}

Amiel, Yoram, Cowell, Frank A., 1999. Thinking About Inequality. Cambridge University Press, Cambridge.

Arneson, Richard, 1989. Equality of opportunity for welfare. Philosophical Studies $56,77-93$.

Arneson, Richard, 1990. Liberalism, distributive subjectivism, and equal opportunity for welfare. Philosophy and Public Affairs 19, 159-194.

Babcock, Linda, Loewenstein, George, Issacharoff, Samuel, Camerer, Colin, 1995. Biased judgments of fairness in bargaining. American Economic Review 85, 13371343.

Cappelen, Alexander W., Sørensen, Erik Ø., Tungodden, Bertil, 2005. Responsibility for what? An experimental approach to fairness and responsibility. University of Oslo: Mimeo. 
Carter, John R., Irons, Michael D., 1991. Are economists different, and if so, why? Journal of Economic Perspectives 5, 171-177.

Cohen, Gerald A., 1989. On the currency of egalitarian justice. Ethics 99, 906-944.

Dworkin, Ronald, 1981. What is equality? Part 2: equality of resources. Philosophy and Public Affairs 10, 283-345.

Engelmann, Dirk, Strobel, Martin, 2004. Inequality aversion, efficiency, and maximin preferences in simple distribution experiments. American Economic Review 94, 857-869.

Fleiss, Joseph L., 1981. Statistical Methods for Rates and Proportions. John Wiley \& Sons, USA.

Fleurbaey, Marc, 1998. Equality among responsible individuals. In Laslier, J-Fr., Fleurbaey, M., Trannoy, A., Gravel, N. (Eds.), Freedom in Economics, Routledge, London.

Fleurbaey, Marc, Maniquet, François, forthcoming. Compensation and Responsibility. Handbook of Social Choice and Welfare, North-Holland.

Fong, Christina, 2001. Social preferences, self-interest, and the demand for redistributions. Journal of Public Economics 82, 225-246.

Frank, Robert H., Gilovich, Thomas D., Regan, Dennis T., 1993. Does studying economics inhibit cooperation? Journal of Economic Perspectives 7, 159-171.

Frank, Robert H., Gilovich, Thomas D., Regan, Dennis T., 1996. Do economists make bad citizens? Journal of Economic Perspectives 10, 187-192.

Frey, Bruno S., Meier, Stephan, 2003. Are political economists selfish and indoctrinated? Evidence from a natural experiment. Economic Inquiry 41, 448-462.

Frohlich, Norman, Oppenheimer, Joe, Eavy, Cheryl, 1987a. Choices of principles of distributive justice in experimental groups. American Journal of Political Science, 606-636.

Frohlich, Norman, Oppenheimer, Joe, Eavy, Cheryl, 1987b. Laboratory results on Rawls's distributive justice. British Journal of Political Science 17, 1-21.

Gaertner, Wulf, 1994. Distributive justice: theoretical foundations and empirical findings. European Economic Review 38, 711-720.

Gaertner, Wulf, Jungeilges, Jochen, Neck, Reinhard, 2001. Cross-cultural equity evaluations: a questionnaire-experimental approach. European Economic Review 45, 953-963. 
Gaertner, Wulf, Jungeilges, Jochen, 2002. Evaluation via extended orderings: empirical findings from Western and Eastern Europe. Social Choice and Welfare 19, 29-55.

Gaertner, Wulf, Schwettmann, Lars, 2005. Equity, responsibility and the cultural dimension. University of Osnabrück: Mimeo.

Heider, Fritz, 1958. The Psychology of Interpersonal Relations. John Wiley \& Sons, New York.

Hu, Yung-An, Liu, Day-Yang, 2003. Altruism versus egoism in human behavior of mixed motives. American Journal of Economics and Sociology 62, 677-705.

Kahneman, Daniel, Knetsch, Jack L., Thaler, Richard, 1986. Fairness as a constraint on profit seeking: entitlements in the market. American Economic Review 76, 728-741.

Konow, James, 2000. Fair shares: accountability and cognitive dissonance in allocation decisions. American Economic Review 90, 1072-1091.

Konow, James, 2003. Which is the fairest one of all? A positive analysis of justice theories. Journal of Economic Literature 11, 1188-1239.

Lissowsky, Grzegorz, Tyszka, Tadeusz, Okrasa, Wlodzimierz, 1991. Principles of distributive justice: experiments in Poland and America. The Journal of Conflict Resolution 35, 98-119.

Marwell, Gerald, Ames, Ruth E., 1981. Economists free ride, does anyone else? Journal of Public Economics 15, 295-310.

McClelland, Gary, Rohrbaugh, John, 1978. Who accepts the Pareto axiom? The role of utility and equity in arbitration decisions. Behavioural Science 23, 446-456.

Rawls, John, 1971. A Theory of Justice. Harvard University Press, Cambridge.

Rawls, John, 1974. Some reasons for the maximin criterion. The American Economic Association 64, 141-146.

Roemer, John E., 1993. A pragmatic theory of responsibility for the egalitarian planner. Philosophy and Public Affairs 22, 146-166.

Sen, Amartya, 1980. Equality of what? In McMurrin, S. (Ed.), The Tanner Lectures on Human Values, Vol. 1, University of Utah Press, Salt Lake City.

Sen, Amartya, 1992. Inequality Reexamined. Oxford University Press, Oxford.

Schokkaert, Erik, Lagrou, Leo, 1983. An empirical approach to distributive justice. Journal of Public Economics 21, 33-52 
Schokkaert, Erik, Overlaet, Bert, 1989. Moral intuitions and economic models of distributive justice. Social Choice and Welfare 6, 19-31.

Schokkaert, Erik, Devooght, Kurt, 2003. Responsibility-sensitive fair compensation in different cultures. Social Choice and Welfare 21, 207-242.

Yaari, Menahem E., Bar-Hillel, Maya, 1984. On dividing justly. Social Choice and Welfare 1, 1-24.

Yezer, Anthony M., Goldfarb, Robert S., Poppen, Paul J., 1996. Does studying economics discourage cooperation? Watch what we do, not what we say or how we play. Journal of Economic Perspectives 10, 177-186.

Zsolnai, Laszlo, 2003. Honesty versus cooperation. American Journal of Economics and Sociology 62, 707-712. 